九州大学学術情報リポジトリ

Kyushu University Institutional Repository

\title{
Ethanol Consumption Influences the Metabolism of Linoleic Acid in Rats
}

Koba, Kazunori

Laboratory of Nutrition Chemistry, Faculty of Agriculture, Kyushu University

Sugano, Michihiro

Laboratory of Nutrition Chemistry, Faculty of Agriculture, Kyushu University

https://doi.org/10.5109/23881

出版情報：九州大学大学院農学研究院紀要. 32 (3/4)，pp. 265-271，1988-03. Kyushu University バージョン：

権利関係 : 


\title{
Ethanol Consumption Influences the Metabolism of Linoleic Acid in Rats
}

\author{
Kazunori Koba and M ichihiro Sugano \\ Laboratory of Nutrition Chemistry, Faculty of Agriculture \\ Kyushu University 46-09, Fukuoka 812 \\ (Received D ecember 5, 1987)
}

\begin{abstract}
The influence of ethanol consumption (on average $4 \mathrm{~g} / \mathrm{kg}$ body weight as a powder) for 26 days on the metabolism of linoleic acid was studied in male rats. Ethanol suppressed the activity of $\Delta^{6}$ desaturase by approximately $50 \%$ but not $\Delta^{5}$ desaturase in liver microsomes. The percentage of linoleic acid in liver phosphatidylcholine was higher in the ethanol than in the control groups while that of arachidonic acid remained unifluenced, resulting in the reduction of the ratio of arachidonate/linoleate. Weekly analyses of serum fatty acids revealed an increasing trend of the concentration of total fatty acids, especially linoleic and arachidonic acid after feeding ethanol. However, the ratio of arachidonate/linoleate became low with the duration of ethanol consumption. There was a decreasing trend of the concentration of plasma and liver cholesterol while that of liver triglyceride tended to increase by ethanol. The results indicate a disturbance by ethanol of the desauration of linoleate to arachidonate presumably as a consequence of the reduction of the hepatic $\Delta^{6}$ desaturase activity.
\end{abstract}

\section{INTRODUCTION}

Chronic administration of ethanol causes an abnormality of the concentration and composition of various lipid components both in humans and animals (Cunnae et al., 1985 : Droitte et al., 1984). Acute consumption of a large amount of ethanol induces fatty liver and hepatocirrhosis, and may also increase the risk of cerebral infarction or hemorrhage (Hillbom et al., 1981). On the other hand, there is a possibility that moderate consumption of ethanol may protect against cardiovascular disease (Gruchow et al., 1982). Although the mechanism causing these alterations is not well defined, it seems that ethanol firstly influences the plasma and liver lipid levels. Chronic ethanol consumption inhibits not only the activity of $\Delta^{6}$ desaturase, a key enzyme in the metabolism of linoleate to arachidonate, but also that of $\Delta^{5}$ desaturase in rat liver (Nervi et al., 1980). However, these multiple effects appear to be influenced significantly by the amount of ethanol consumed.

In the present study, we investigated the effects of relatively long term consumption of a high level of ethanol on plasma and liver fatty acid profiles and the activities of $\Delta^{6}$ and $\Delta^{5}$ desaturase of liver microsomes of rats.

\section{MATERIALS AND METHODS}

\section{Animals and Diets}

Male Sprague-Dawley rats (Seiwa Experimental Animals, Yoshitomi) weighing 
approximately $100 \mathrm{~g}$ were housed individually in an air-conditioned room $\left(20-23^{\circ} \mathrm{C}\right.$, lights on 0800 to 2000 hours) and fed commercial rat chow (Type NMF, Oriental Yeast Co., Tokyo) for 4 days. Rats were then fed experimental diets freely for 26 days. The compsotion of the basal diet was in weight percent ; casein 20, corn oil 10, mineral mixture 3.5, vitamin mixture 1 , choline bitartrate 0.2 , DL-methionine 0.3 , cellulose 5, corn starch 15, and sucrose to 100. Either powdered ethanol in dextrin (Alcock, Sato Shokuhin Kogyo Co., Komaki) or glucose in dextrin (control diet) were added at the final level of $5.1 \%$ ethanol or glucose with $11.1 \%$ dextrin at the expense of sucrose. Mineral and vitamin mixtures according to $\mathrm{AIN}^{76}$ (American Institute of Nutrition, 1977) were purchased from Oriental Yeast Co. A small volume of blood was withdrawn from the teil vein weekly at 1330 to 1430 hours after depriving of the diet at 0830 hours for the measurement of fatty acids. At the end of the experiment, rats were lightly anesthetized with diethylether and blood was collected from the abdominal aorta in a syringe containing 3.8\% $\mathrm{Na}_{3}$-citrate $(1 \mathrm{ml}$ for $9 \mathrm{ml}$ blood) for analysis of lipid components. Liver was excised immediately.

\section{Lipid Analyses}

Plasma and liver lipids extracted by a mixture of chloroform-methanol $(2: 1, \mathrm{v} /$ v) were analyzed for cholesterol, triglyceride and phospholipid (Nagata et al., 1980). Liver phosphatidylcholine was separated by thin-layer chromatography and the fatty acid composition was analayzed by gas-liquid chromatography on a DEGS column (Sugano et al., 1984). Sera separated from the weekly blood samples were extracted by the method of Bligh-Dyer (1959) and fatty acid contents were measured by gas-liquid chromatography using pentadecanoic acid as a standard.

\section{Measurements of $\Delta^{6}$ and $\Delta^{5}$ Desaturase Activities}

The $\Delta^{6}$ and $\Delta^{5}$ desaturase activities in liver microsomes were measured using [1 $\left.{ }^{-14} \mathrm{C}\right]$ linoleic acid $(59 \mathrm{mCi} / \mathrm{mmol})$ and $\left[2-{ }^{14} \mathrm{C}\right]$ eicosatrienoic acid $(56 \mathrm{mCi} / \mathrm{mmol})$ purchased from Amersham International plc, Buckinghamshire according to the method of Sevensson (1983).

\section{Statistical Analysis}

Data were analyzed by the Student's t-test.

\section{RESULTS}

\section{Growth Performance}

Dietary ethanol neither influenced food intake nor body weight gain (Table 1). Thus, food efficiency was same between the two groups $(0.37 \pm 0.00$ vs. $0.39 \pm 0.01$ for the ethanol and control groups, respectively). Also, ethanol did not influence relative liver weight $(\mathrm{g} / 100 \mathrm{~g}$ body weight).

\section{Plasma and Liver Lipids}

As shown in Table 2, the concentration of plasma lipids was in general comparable between the ethanol and control groups, except for the decreasing trend of cholesterol due to feeding ethanol. The concentration of liver cholesterol also tended 
Table 1. Growth performance and liver weight.

\begin{tabular}{|c|c|c|c|c|}
\hline \multirow{2}{*}{ Groups } & \multicolumn{2}{|c|}{ Body weight $(g)$} & \multirow{2}{*}{$\begin{array}{l}\text { Food intake } \\
\text { (g/day) }\end{array}$} & \multirow{2}{*}{$\begin{array}{c}\text { Relative liver } \\
\text { weight (g/100g } \\
\text { body weight) }\end{array}$} \\
\hline & Initial & Gain & & \\
\hline Control & $106 \pm 2$ & $193 \pm 4$ & $18.8 \mathrm{f} 0.5$ & $4.94 \mathrm{f} 0.2$ \\
\hline Ethanol & $106 \pm 2$ & $188 \pm 6$ & $19.4 \pm 0.5$ & $4.91 \pm 0.1$ \\
\hline
\end{tabular}

Values are means $\pm \mathrm{SE}$ of 6 rats.

Table 2. Concentrations of plasma and liver lipids.

\begin{tabular}{cccccccc}
\hline \multirow{2}{*}{ Groups } & \multicolumn{3}{c}{ Plasma $(\mathrm{mg} / \mathrm{dl})$} & & \multicolumn{3}{c}{ Liver $(\mathrm{mg} / \mathrm{g})$} \\
\cline { 2 - 4 } \cline { 6 - 8 } & CHOL & TG & PL & & CHOL & TG & PL \\
\hline Control & $76.9 \pm 9.9$ & $220 \pm 32$ & $181 \pm 15$ & & $3.94 \mathrm{f} 0.39$ & $33.8 \pm 8.0$ & $27.8 \pm 0.8$ \\
Ethanol & $63.3 \pm 8.5$ & $240 \pm 33$ & $175 \pm 16$ & & $3.27 \pm 0.26$ & $42.6 \pm 6.4$ & $26.8 \mathrm{t} 0.4$ \\
\hline
\end{tabular}

Values are means \pm SE of 6 rats.

CHOL : cholesterol, TG : triglyceride, PL : phospholipid

to be low whereas that of triglyceride was seemingly high in the ethanol group.

\section{Serum Fatty Acid Concentrations}

Changes in concentrations of serum total fatty acids are summarized in Table 3. Concentrations of total fatty acids temporary decreased after replacing chow by purified diets, but they restored to the starting level in two weeks. In rats fed an ethanol diet, the concentration continued to increase throughout the experiment while in the control rats it reached plateau in two weeks, thus the difference between groups became greater as the feeding period elapsed. Although the difference was seen in almost all component fatty acids, the percentage of linoleate was significantly higher after 3 weeks, The ratio of arachidonate/linoleate tended to be low with the duration of ethanol feeding.

\section{Fatty Acid Compositions of Liver Phosphatidylcholine}

As Table 4 shows, the percentage of linoleic acid in liver phosphatidylcholine was moderately but significantly higher in the ethnool group than in the control group while that of arachidonic acid was comparable. Consequently, the ratio of arachidonate/ linoleate was to some extent lower in rats fed an ethanol diet.

\section{Activities of $\Delta^{6}$ and $\Delta^{5}$ Desaturase}

The $\Delta^{6}$ desaturase activity in liver microsomes was suppressed by ethanol to approximately one-half that of control rats, although the difference was not statistically significant due to a large individual variation (Fig. 1). The activity of $\Delta^{5}$ desaturase was markedly higher than that of $\Delta^{6}$ desaturase, but no ethanol-effect was observed. 
Table 3. Time course of serum fatty acid concentrations.

\begin{tabular}{|c|c|c|c|c|c|c|c|}
\hline \multirow{3}{*}{ Fatty acids } & \multicolumn{7}{|c|}{ Feeding periods (weeks) } \\
\hline & \multirow[t]{2}{*}{0} & \multicolumn{2}{|c|}{1} & \multicolumn{2}{|c|}{2} & \multicolumn{2}{|c|}{3} \\
\hline & & Control & Ethanol & Control & Ethanol & Control & Ethanol \\
\hline \multicolumn{8}{|c|}{$(\mathrm{ml} / \mathrm{dl})$} \\
\hline $14: 0$ & $2.8 \mathrm{f} 0.3$ & $1.1 \pm 0.1$ & $2.7 \pm 1.2$ & $2.1 \mathrm{f} 0.2$ & $2.5 \mathrm{f} 0.2$ & $3.1 \mathrm{f} 0.6$ & $2.2 \pm 0.3$ \\
\hline $16: 0$ & $53.8 \pm 3.0$ & $26.2 \pm 1.2$ & $28.5 \pm 2.4$ & $50.4 \pm 4.9$ & $56.5 \pm 3.7$ & $60.2 \pm 8.4$ & $75.4 \mathrm{f} 5.1$ \\
\hline $16: 1$ & $8.0 \mathrm{f} 0.8$ & $3.0 \pm 0.4$ & $5.4 \pm 1.7$ & $8.0 \mathrm{f} 1.2$ & $7.9 \mathrm{f} 0.8$ & $9.4 \mathrm{f} 3.0$ & $11.6 \mathrm{f} 1.4$ \\
\hline $18: 0$ & $29.2 \pm 1.1$ & $13.4 \mathrm{f} 1.2$ & $12.4 \mathrm{f} 1.7$ & $33.4 \pm 2.6$ & $34.5 \mathrm{f} 1.6$ & $36.3 \mathrm{f} 3.1$ & $40.0 \pm 2.4$ \\
\hline $18: 1$ & $51.4 \pm 4.0$ & $19.2 \mathrm{f} 1.8$ & $14.6 \pm 1.3$ & $43.3 \pm 5.1$ & $45.3 \mathrm{f} 4.8$ & $52.3 \pm 11.6$ & $70.4 \mathrm{f} 5.7$ \\
\hline $18: 2$ & $78.4 \pm 5.9$ & $30.6 \mathrm{f} 1.2$ & $29.6 \mathrm{f} 1.7$ & $55.0 \mathrm{f} 5.4$ & $64.8 \mathrm{f} 7.8$ & $57.0 \pm 7.6$ & $86.5 \pm 5.9^{*}$ \\
\hline $18: 3(\mathrm{n} 6)$ & $1.4 \pm 0.1$ & $0.8 \pm 0.1$ & $1.6 \mathrm{f} 0.6$ & $1.2 \mathrm{i} 0.3$ & $1.2 \mathrm{f} 0.2$ & $1.7 \mathrm{f} 0.4$ & $1.7 \pm 0.2$ \\
\hline $18: 3(\mathrm{n} 3)$ & $2.4 \mathrm{f} 0.2$ & $1.4 \mathrm{f} 0.4$ & $1.3 \mathrm{f} 0.3$ & 1.3 to. 2 & $1.8 \mathrm{f} 0.2$ & $1.9 \pm 0.3$ & $2.5 \pm 0.2$ \\
\hline $20: 3(\mathrm{n} 3)$ & $1.2 \pm 0.1$ & $0.4 \pm 0.1$ & $0.1 \pm 0.1^{*}$ & 1.0 to. 2 & $1.4 \mathrm{f} 0.2$ & $1.2 \mathrm{i} 0.4$ & $2.0 \mathrm{f} 0.2$ \\
\hline $20: 4(n 6)$ & $51.5 \pm 3.0$ & $26.4 \mathrm{f} 2.7$ & $27.7 \pm 2.2$ & $88.3 \mathrm{i} 7.3$ & $92.6 \pm 4.9$ & $93.0 \pm 13$ & $114 \pm 6.9$ \\
\hline $20: 5(\mathrm{n} 3)$ & $1.7 \mathrm{f} 0.2$ & $1.1 \mathrm{fO} .1$ & $2.1 \mathrm{f} 0.6$ & $1.1 \mathrm{fO} .1$ & $1.0 \pm 0.1$ & $1.2 \pm 0.1$ & $1.1 \pm 0.1$ \\
\hline $22: 4(\mathrm{n} 6)$ & & $1.8 \pm 0.4$ & $3.6 \mathrm{fl} .1$ & $3.4 \mathrm{f} 0.5$ & 4.5 -to. 5 & $4.2 \mathrm{f} 0.8$ & $6.3 \mathrm{f} 0.7$ \\
\hline $22: 5(\mathrm{n} 6)$ & & $1.4 \pm 0.4$ & $1.5 \pm 0.3$ & $4.1 \pm 1.0$ & 5.110 .6 & $4.7 \pm 1.8$ & $6.5 \pm 0.9$ \\
\hline $22: 5(\mathrm{n} 3)$ & $1.3 \pm 0.1$ & $0.3 \pm 0.1$ & $0.1 \pm 0.1$ & $0.5 \pm 0.1$ & $0.7 \pm 0.1$ & $0.6 \pm 0.1$ & $1.0 \pm 0.1^{*}$ \\
\hline $22: 6(\mathrm{n} 3)$ & $9.7 \mathrm{t} 0.7$ & $4.3 \mathrm{f} 0.4$ & $5.4 \pm 0.4$ & $6.8 \mathrm{f} 0.4$ & $7.5 \mathrm{f} 0.4$ & $6.1 \pm 0.8$ & $8.6 \pm 0.3^{*}$ \\
\hline Total & $293 \pm 16$ & $131 \pm 9$ & $137 \pm 9$ & $295 \pm 25$ & $326 \pm 19$ & $331 \pm 50$ & $430 \pm 28$ \\
\hline $20: 4 / 18: 2$ & $0.7 \pm 0.1$ & $0.9 \pm 0.1$ & $1.0 \pm 0.1$ & $1.7 \pm 0.2$ & $1.5 \mathrm{f} 0.2$ & $1.7 \mathrm{f} 0.2$ & $1.3 \pm 0.1$ \\
\hline
\end{tabular}

Values are means $\pm \mathrm{SE}$ of 6 rats.

* Significantly different from the corresponding control group $\mathrm{P}<0.05$.

Table 4. Fatty acid compositions of liver phosphatidylcholine.

\begin{tabular}{|c|c|c|c|}
\hline \multirow{2}{*}{ Fatty } & \multirow{2}{*}{ acids } & \multicolumn{2}{|c|}{ Groups } \\
\hline & & Control & Ethanol \\
\hline & & \multicolumn{2}{|c|}{ (weight \%) } \\
\hline 14 & 0 & $1.8 \mathrm{f} 0.4$ & $1.1 \pm 0.4$ \\
\hline 16 & 0 & $22.6 \pm 1.0$ & $23.5 \pm 0.6$ \\
\hline 16 & 1 & $4.3 \pm 0.9$ & $3.1 \mathrm{f} 0.5$ \\
\hline 18 & 0 & $17.9 \mathrm{fl} .1$ & $18.8 \pm 0.8$ \\
\hline 18 & 1 & $10.9 \mathrm{f} 1.2$ & $10.0 \pm 0.5$ \\
\hline 18 & 2 & $7.3 \pm 0.4$ & $8.4 \pm 0.2^{*}$ \\
\hline 18 & $3(n 6)$ & $0.3 \pm 0.0$ & $0.2 \pm 0.0$ \\
\hline 18 & 3 (n3) & $0.5 \pm 0.1$ & $0.4 \pm 0.0$ \\
\hline 20 & $3(\mathrm{n} 3)$ & $0.5 \pm 0.1$ & $0.7 \pm 0.1$ \\
\hline 20 & $4(\mathrm{n} 6)$ & $26.2+2.2$ & $25.6 \mathrm{f} 0.7$ \\
\hline 20 & $5(\mathrm{n} 3)$ & $0.6 \pm 0.1$ & $1.1 \mathrm{f} 0.2$ \\
\hline 22 & 4 (n6) & $0.6 \pm 0.1$ & $0.6 \pm 0.1$ \\
\hline 22 & $5(\mathrm{n} 6)$ & $2.9 \pm 0.4$ & $2.8 \pm 0.1$ \\
\hline 22 & $5(\mathrm{n} 3)$ & $0.2 \pm 0.0$ & $0.2 \pm 0.0$ \\
\hline 22 & $6(\mathrm{n} 3)$ & $3.6 \mathrm{f} 0.2$ & $3.5 \pm 0.1$ \\
\hline
\end{tabular}

Values are means $\pm \mathrm{SE}$ of 6 rats

* Significantly different at $\mathrm{p}<0.05$. 


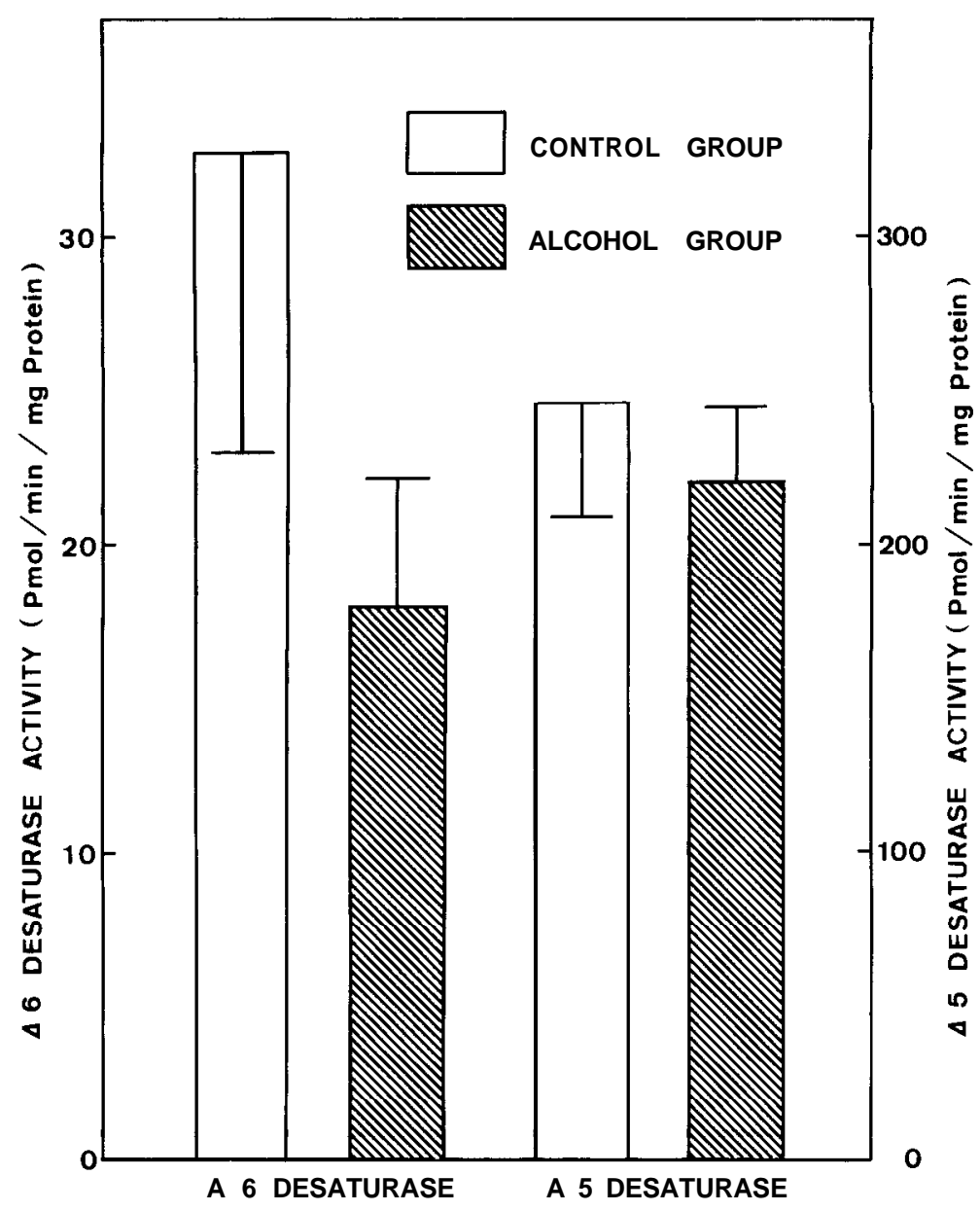

Fig. 1. $\Delta^{5}$ and $\Delta^{6}$ Desaturase activities of rats liver microsomes.

\section{DISCUSSION}

Ethanol is oxidized to acetaldehyde either by cytosolic NADH-dependent alcohol dehydrogenase or microsomal ethanol oxidizing system (MEOS) (Lieber et al., 1970). Acetaldehyde is further oxidized to acetate by mitochondrial aldehyde dehydrogenase. The oxidation of NADH is the rate limiting step both in the cytosolic and mitochondrial oxidation systems and MEOS proceeds with the oxidation of NADPH (Lieber et al., 1970). The $\Delta^{6}$ and $\Delta^{5}$ desaturase reactions also proceed coupled with the oxidation of NADH or NADPH by microsomal cytochrome-b, (Nervi et al., 1980). Since ethanol is metabolized in preference to various nutrients in the liver, there may be a possibility that desaturation of polyunsaturated fatty acid is suppressed by ethanol due to a shortage of the supply of NADH or NADPH. Although $\Delta^{6}$ desaturase activity tended to reduce by ethanol, the $\Delta^{5}$ desaturase activity was not influenced in the present study 
(Fig. 1). A decidedly high activity of $\Delta^{5}$ desaturase in relation to $\Delta^{6}$ desaturase may in part be responsible for the lack of the ethanol-effect. The amount of ethanol consumed should also be taken into consideration since chronic consumption of the large amount of ethanol leads to a reduction of both $\Delta^{5}$ and $\Delta^{6}$ desaturation (Nervi et al., 1980).

Concentrations of serum linoleate and arachidonate gradually increased by ethanol without influencing relative percentages of these polyunsaturated fatty acids, suggesting at least an exaggerated secretion as lipoproteins by the liver. NADPH produced during. the metabolism of ethanol is used for the synthesis of fatty acids in the liver (Lieber, 1968). Acute ethanol intake has been known to increase the serum triglyceride level (Schapiro et al., 1965 ; Scheig et al., 1963). However, it is likely that the degree of an increase in serum triglyceride differs depending on the route of ethanol administration, acute or chronic, or on the amount of ethanol consumed. The amount of ethanol consumed in the present study seems to be within the limit of tolerance that modifies hepatic tryglyceride metabolism, on average $4 \mathrm{~g} / \mathrm{kg}$ body weight per day.

Laurie et al. (1986) investigated the effects of the different levels of ethanol (2 and $10 \mathrm{~g} / \mathrm{kg}$ body weight per day) on changes in lipid compositions of rats and found a significant increase in the percentage of linoleic acid in phosphatidylcholine of heart mitochondria even when the lower level of ethanol was consumed while that of arachidonate remained uninfluenced. The same trend of the change was observed in the fatty acid composition of liver phosphatidylcholine in the present study. These results suggest an inhibition by ethanol of $\Delta^{6}$ desaturase activity of the liver in consistent with those observed here.

Leferre et al. (1972) reported in rats that an increase in liver and serum cholesterol by ethanol was associated with both enhanced cholestero-genesis and decreased bile acid excretion. In the present study, however, ethanol induced a decrease in the liver and plasma cholesterol level (Table 2), suggesting a reduction of the pool size of body cholesterol. Thus, even in this respect, the effect of ethanol on cholesterol metabolism appears to differ depending on the amount consumed. Ethanol is metabolized by coupling with oxidation of NADH through the microsmal cytochrome-b, and cytochrome p-450 (Nervi et al., 1980). These cytochromes simultaneously catalyze the enzymatic processes involved in cholesterol synthesis and oxidation. In this context, it seemed that the synthesis and catabolism of cholesterol is presumably be suppressed by ethanol. Since ethanol induces reduction of cholesterol excretion (Hostmark et al., 1987), the decrease in the liver cholesterol level in the present study may be attributable to the depression of cholesterol synthesis.

Chronic ethanol consumption interferes with lipid metabolism by competing $\mathrm{NADH}$ with the metabolism of ethanol itself. On the other hand, ethanol may rather have some desirable effects such as a reduction of liver and plasma cholesterol, an increase in HDL-cholesterol or an inhibition of proaggregative and vasocontructive thormboxane A, formation in platelets (Kontula et al., 1982 ; Toivanen et al., 1983 ; Ylikorkala et al., 1987).

The varying effects of ethanol on several lipid parameters appear to depend on the amount consumed. Ethanol when consumed a relatively large amount as employed in the present study tended to reduce the desaturation of linoleate and, hence, formation of arachidonate, a substrate for the eicosanoids. The significance of these changes 
remained to be clarified.

\section{REFERENCES}

American Institute of Nutrition 1977 Report of the American Institute of Nutrition Ad Hoc Committe on Standards for Nutritional Studies. J.Nutr., $107: 1340-1348$

Bligh, E. G. and W. J. Dyer 1959 A rapid method of total lipid extraction and purification. Can. J. Biochem. Physiol., 37 : 911-917

Cunnane, S. C., M. S. Mank and D. F. Horrobin 1985 Effect of ethanol on liver triglycerides and fatty acid composition in the golden Syrian hamster. Ann. Nutr. Metab., $29: 246-252$

Droitte, L. P., Y. Lamboeuf and G. de Saint-Blanquat 1984 Membrane fatty acid changes and ethanol tolerance in rat and mouse. Life Sci., 35:1221-1229

Droitte, L. P., Y. Lamboeuf, G. de Saint-Blanquat and J. -P. Bezaury 1984 Sensitivity of individual erythrocyte membrane phospholipids to changes in fatty acid composition in chronic alcoholic patients. Alcoholism Clin.Exp.Res., 9: 135-137

Gruchow, H. W., R. G. Hoffmann, A. J. Anderson and J. J. Barboriak 1982 Effects of drinking patterns on the relationship between alcohol and coronary occlusion. Atherosclerosis, $43: 393-404$

Hillbom, M. and M. Kaste 1981 Ethanol intoxication : A risk factor for ischemic brain infarction in adolescents and young adults. Stroke, $12: 422-425$

Hillbom, M. and M. Kaste 1981 Does alcohol intoxication precipitate aneurysmal subarachnoidal haemorrhage ?J.Neurol. Neurosurg. Psychiatry, $44: 523-526$

Hostmark, A. T., A. Haug, 0. Spydevold, E. Eilertsen and E. Lystad 1987 Plasma lipoproteins and fecal cholesterol excretion in rats drinking ethanol or beer. Nutr.Res., $7: 843-850$

Kontula, K., L. Viinikka, 0. Ylikorkala and R. Ylikahri 1982 Effects of acute ethanol intake on thromboxane and prostacyclin in human. Life Sci., 31: 261-264

Laurie, F., Y. S. Grace and Y. S. Albert 1986 Changes in lipid composition of rat heart mitochondria after chronic ethanol administration. Alcoholism Clin. Exp. Res., 10 : 606-609

Lefevre, A. F., L. M. DeCarli and C. S. Lieber 1972 Effect of ethanol on cholesterol and bile acid metabolism. J. Lipid Res., 13: 48-55

Lieber, C. S. 1968 Metabolic effects produced by alcohol in the liver and other tissues. Adv. intern. Med., 14: 151-199

Lieber, C. S. and L. M. DeCarli 1970 Hepatic microsomal ethanol-oxidizing system. J.Biol. Chem., $245: 2505-2512$

Nagata, Y., K. Imaizumi and M. Sugano 1980 Effects of soya-bean and casein on serum cholesterol levels in rats. Brit. J.Nutr., $44: 113-121$

Nervi, A. M., R. 0. Peluffo, R. R. Brenner and A. I. Leikin 1980 Effect of ethanol administration on fatty acid desaturation. Lipids, $15: 263-268$

Schapiro, R. H., R. L. Scheig, G. D. Drummey, J. H. Mendelson and K. J. lsselbacher 1965 Effect of prolonged ethanol ingestion of transport and metaboslism of lipids in man. New Eng. J. Med., $272: 610-615$

Scheig, R. L. and K. J. Isselbacher 1963 Effects of ethanol on the liver : Evidence for the preferential synthesis of triglycerides. J.Clin. Invest., $42: 975$

Sugano, M., K. Ryu and T. Ide 1984 Cholesterol dynamics in rats fed cis- and trans-octadecenoate in the form of triglyceride. J. Lipid Res., 25: 474-485

Svensson, L. 1983 The effect of dietary partially hydrogenated marine oils on desaturation of fatty acids in rat liver microsomes. Lipids, $18: 171-178$

Toivanen, J., 0. Ylikorkala and L. Viinikka 1983 Ethanol inhibits platelet thromboxane A, production but has no effect on lung prostacyclin synthesis in humans. Thromb. Res., 33:1-8

Ylikorkala, O., E. Halmesmaki and L. Viinikka 1987 Effect of ethanol on thromboxane and prostacyclin synthesis by fecal platelets and umbilical artery. Life Sci., 41: 371-376 